\title{
The temperature and pre-crack length effects on delamination resistance of woven GFRP sandwich composites
}

\author{
Meltem Evren Toygar*, Farshid Khosravi Maleki** \\ *Dokuz Eylül University, Engineering Faculty, Mechanical Engineering Department, 35397 Tinaztepe Campus \\ Buca/Izmir, Turkey, E-mail: evren.toygar@deu.edu.tr \\ **Dokuz Eylül University, Engineering Faculty, Mechanical Engineering Department, 35397 Tinaztepe Campus \\ Buca/Izmir, Turkey, E-mail: farshid.khosravi09@gmail.com
}

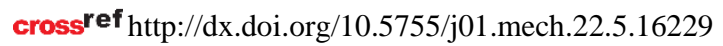

\section{Introduction}

Nowadays, sandwich composites have been adopted in various areas such as aerospace, marine and automotive sectors due to the constructed with two stiff, strong face sheets and a lightweight, relatively flexible core, and a high bending stiffness and strength per unit weight. Therefore, their fuel efficiency in transportation vehicles, but at present, there is a strong interest in the development and applications of sandwich structures for civil and building material systems [1]. However, sandwich construction has a number of problems due to existence of interfaces serves as a source of problem such as failure initiation and growth. Therefore, the test methods have been developed to obtain the interlaminar fracture toughness of sandwich composites by considering environmental effects, a suitable test configuration or specimen geometry under Mode I or Mode II loading. The presence and growth of delamination in laminates significantly reduces the compressive load-carrying capacity of a structure and causes initiation of catastrophic failure [2]. Several methods have emerged in the past for computing strain energy release rates for delamination growth in a wide variety of composite structures. The strain energy release rate was obtained by using double cantilever beam (DCB) specimens for honeycomb sandwich composites. The analytical model is established by considering delamination and embedded artificial pre-crack, and the results obtained from 3D finite element analysis for various delamination lengths have been compared with the analytical results [3, 4]. To investigate the fracture behavior of honeycomb sandwich panels containing embedded artificial pre-crack, DCB test geometry was used to get strain energy release rate. Here, the facesheet is made of carbon fibre pre-preg and the core was honeycomb [4] and an experimental study is conducted on the interlaminar fracture of honeycomb sandwich. Development and evaluation of fracture mechanics test methods for sandwich composites have been done [5] to characterize Mode I and Mode II energy release rate associated with face sheet/core delamination growth in sandwich composites. An experimental study has been done to investigate the face sheet/core interfacial fracture toughness of E-Glass/Vinylester face sheet, with PVC core sandwich composites [6]. The experimental studies were performed at room temperature and cryogenic temperatures to provide basic material properties and critical fracture parameters deal with failure [7,8]. Carbon fibre reinforced faceplate debonding under mode I loading in sandwich structures at room and high temperatures has been investigated [9]

The virtual crack closure technique (VCCT) is widely used for computing energy release rates, based on results from continuum (2D) and solid (3D) finite element (FE) analyses, and to supply the mode separation required when using mixed-mode fracture criteria $[10,11]$.

In this study, the temperature and pre-crack effects on the delamination resistance of woven GFRP sandwich composites under Mode I loading was experimentally investigated and numerically modelled. GFRP sandwich panel was fabricated with vacuum assisted resin infusion melding (VARIM) at the composite laboratory of Mechanical Engineering Department, Dokuz Eylül University. The mechanical properties were obtained at room and high temperature. DCB test was adopted for the measurement of delamination resistance by evaluating the SERR value to obtain the fracture properties of woven GFRP sandwich composites. The three analytical methods, the experimental compliance calibration method (CCM), Modified Compliance Calibration Method (MCC) and Modified Beam Theory (MBT) have been used. In the finite element analysis virtual crack closure technique (VCCT) was used. The results obtained from 3D finite element analysis for various delamination lengths compare well with the experimental results. It is seen that there is an agreement between experimental and numerical results so that VCCT analysis is to be an appropriate method for analysing a SERR value of sandwich composites.

\section{Material and method}

\subsection{Materials and specimens preparation}

In this study, the sandwich composite panel was fabricated with vacuum assisted resin infusion melding (VARIM) at the composite laboratory of Mechanical Engineering Department, Dokuz Eylul University. The panel was fabricated with a woven GFRP (Glass Fibre Reinforced Polymer) face sheets that properties and plies of the upper and lower face sheets are listed in Table 1. The resin used in this study was comprised of epoxy resin (Hexion MGS L160 with a density of $1.13 \mathrm{gr} / \mathrm{cm} 3$ ) and hardener (Hexion MGS H160 with a density of $0.96 \mathrm{gr} / \mathrm{cm} 3$ ) for a resin-hardener ratio of a 100:25 by weight. As a sandwich core material, Airex ${ }^{\circledR}$ C70.55 was used. The properties of core is given in Table 2 .

The laminates were cured at room temperature for 4 days and post-cured at $80^{\circ} \mathrm{C}$ for $8 \mathrm{~h}$. To create a precrack, Teflon film was placed at the plane between Upper 
face sheet and foam during the lay-up process. Tests were performed in a universal testing machine (Shimadzu AG100). All samples were cut by a water-cooled tile saw for tests in accordance with ASTM's.

Table 1

The properties and sequence of upper and lower face sheets

\begin{tabular}{|c|c|c|c|}
\hline \multirow{4}{*}{$\begin{array}{c}\text { Upper Face } \\
\text { sheet }\end{array}$} & $\begin{array}{c}\text { Order of } \\
\text { Lamina }\end{array}$ & $\begin{array}{c}\text { Distribution } \\
\text { of fibres }\end{array}$ & $\begin{array}{c}\text { Unit mass, } \\
\mathrm{Kg} / \mathrm{m}^{2}\end{array}$ \\
\cline { 2 - 4 } & 1 & Randomly & 0.45 \\
\cline { 2 - 4 } & 2 & Woven & 0.80 \\
\cline { 2 - 4 } & 3 & Woven & 0.80 \\
\hline \multirow{4}{*}{$\begin{array}{c}\text { Lower face } \\
\text { sheet }\end{array}$} & 5 & Woven & 0.80 \\
\cline { 2 - 4 } & 2 & Woven & 0.80 \\
\cline { 2 - 4 } & 3 & Woven & 0.80 \\
\cline { 2 - 4 } & 4 & Woven & 0.80 \\
\hline
\end{tabular}

Properties of Airex ${ }^{\circledR}$ C70.55 foam core

Table 2

\begin{tabular}{|c|c|c|c|}
\hline $\begin{array}{c}\text { Density, } \\
\mathrm{Kg} / \mathrm{m}^{3}\end{array}$ & $\begin{array}{c}\text { Tensile } \\
\text { strength, } \\
\mathrm{N} / \mathrm{mm}^{2}\end{array}$ & $\begin{array}{c}\text { Tensile } \\
\text { modulus, } \\
\mathrm{N} / \mathrm{mm}^{2}\end{array}$ & $\begin{array}{c}\text { Shear } \\
\text { modulus, } \\
\mathrm{N} / \mathrm{mm}^{2}\end{array}$ \\
\hline 60 & 1.3 & 45 & 22 \\
\hline
\end{tabular}

\subsection{Face sheet's tests}

Tensile properties of face sheets were measured by ASTM D3039/3039M-08 [12] and specimens were prepared according to the ASTM suggestion. Tests were performed at room temperature $23^{\circ} \mathrm{C}$ and at high temperature $60^{\circ} \mathrm{C}$ with a crosshead speed of $2 \mathrm{~mm} / \mathrm{min}$. Shear properties were obtained according to ASTM D3518/D3518M-13 [13]. Strain gauge was used to determine the mechanical properties [14]. During tests, force versus stroke values were recorded. Obtained results are shown in Table 3.

Table 3

Mechanical properties of GFRP face sheets

\begin{tabular}{|c|c|c|c|c|c|c|}
\hline & \multicolumn{2}{|c|}{$\begin{array}{c}\text { Poisson } \\
\text { ratio }\end{array}$} & \multicolumn{2}{c|}{$\begin{array}{c}\text { Modulus of } \\
\text { elastisity, GPa }\end{array}$} & $\begin{array}{c}\text { Shear } \\
\text { Modulus, } \\
\text { GPa }\end{array}$ \\
\hline & $v_{12}$ & $v_{13}$ & $E_{11}$ & $E_{22}$ & $E_{33}$ & $G_{12}$ \\
\hline $\begin{array}{c}\text { Room } \\
\text { temp. }\end{array}$ & 0.26 & 0.3 & 21 & 21 & 10 & 3.7 \\
\hline $60^{\circ} \mathrm{C}$ & 0.24 & 0.28 & 19 & 19 & 8 & 3.5 \\
\hline
\end{tabular}

\subsection{DCB test procedures}

DCB specimens were prepared with dimensions of $b=25 \mathrm{~mm}$ in width, $L=200 \mathrm{~mm}$ in length, and with $a_{0}=37,57$, and $77 \mathrm{~mm}$ initial crack lengths as shown in Fig. 1. Aluminium piano hinges were adhesively bonded to the face sheets. The bonding surface of the specimens were sanded with sandpaper, then wiped clean with an acetone to remove any contamination.
The test plan was constructed to investigate the strain energy release rate as a function of temperature and pre-crack. The two test temperatures, room temperature $\left(23^{\circ} \mathrm{C}\right)$ and high temperature $\left(60^{\circ} \mathrm{C}\right)$ and three different pre-cracks 37, 57, $77 \mathrm{~mm}$ (see Fig. 1) were investigated. At least 4 replicates for each test condition and pre-crack values were used to develop the final data. The mode I tests were carried out on a universal testing machine at room and high temperature condition as shown in Figs. 2 and 3 for different pre-crack values as mentioned. Displacement controlled tests were conducted at a crosshead displacement rate of $0.5 \mathrm{~mm} / \mathrm{min}$. Load and crosshead displacement were recorded throughout the test. Experiments were continued up to $50 \mathrm{~mm}$ crack progress. At least four each specimens were tested for each pre-crack and temperature condition.

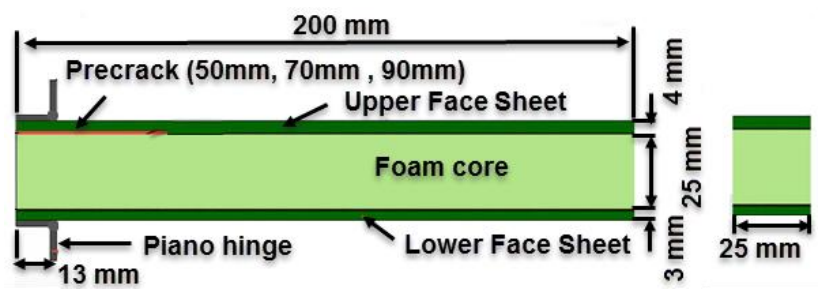

Fig. 1 DCB specimen details

At high temperature condition, after specimens were mounted to the machine, the jaws of the device and the specimen were entered into the cabin and waiting for 30 minutes to reach the stable $60^{\circ} \mathrm{C}$ to perform test.

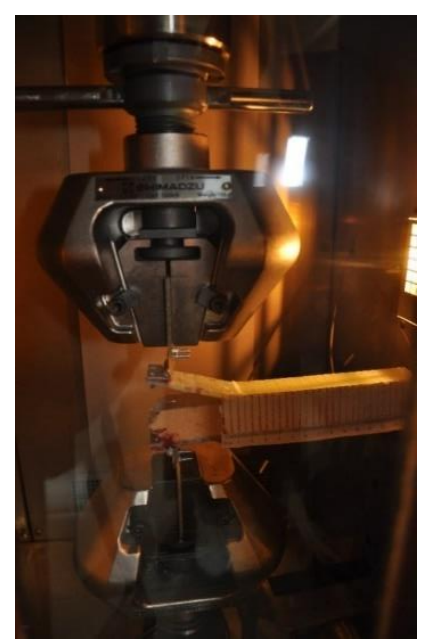

Fig. 2 DCB test setup

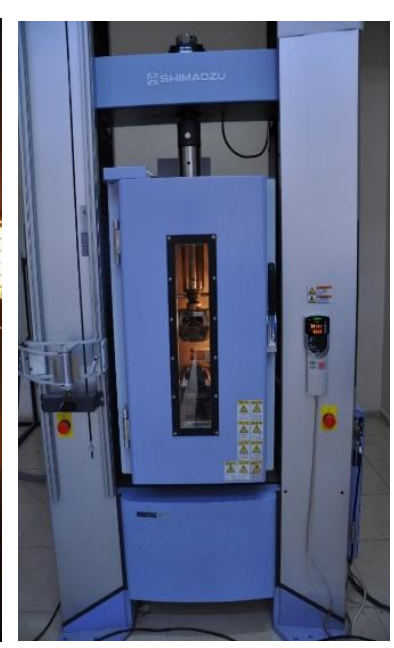

Fig. 3 Cabin with $60^{\circ} \mathrm{C}$ temperature
Methods for calculating energy release rates

The mode I critical energy release rates can be calculated by methods explained in ASTM Standard D5528 [15]. These consisted of a modified beam theory (MBT), a compliance calibration method (CC) and a modified compliance calibration method (MCC).

\section{Modified Beam Theory (MBT)}

The beam theory expression for the strain energy release rate of a perfectly built-in (that is, clamped at the delamination front) double cantilever beam is as follows: 


$$
G_{I C}=\frac{3 P \delta}{2 b a}
$$

where $P$ is load; $\delta$ is load point displacement; $b$ is specimen width and $a$ is delamination length.

In practice, this expression will overestimate GI because the beam is not perfectly built-in (that is, rotation may occur at the delamination front). One way of correcting for this rotation is to treat the DCB as if it contained a slightly longer delamination, $a+|\Delta|$, where $\Delta$ may be determined experimentally by generating a least squares plot of the cube root of compliance, $C^{1 / 3}$, as a function of delamination length (Fig. 4). The compliance, $C$, is the ratio of the load point displacement to the applied load, $\delta / P$. The values used to generate this plot should be the load and displacements corresponding to the visually observed delamination onset on the edge and all the propagation values. Mode I interlaminar fracture toughness is calculated as follows:

$$
G_{I C}=\frac{3 \times P \times \delta}{2 \times b\left(a_{0}+|\Delta|\right)},
$$

where $P$ is load; $\delta$ is load point displacement; $b$ is Specimen width; $a_{0}$ is initial delamination length and $\Delta$ is effective delamination extension to correct for rotation of DCB arms at delamination front.

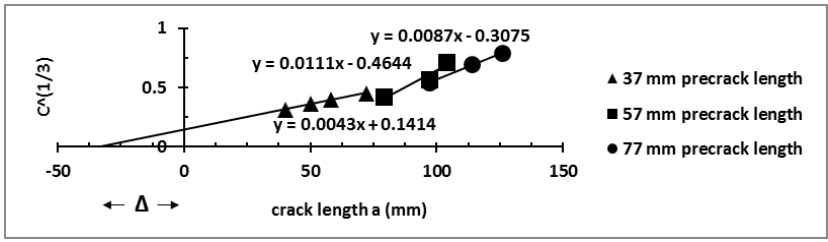

a

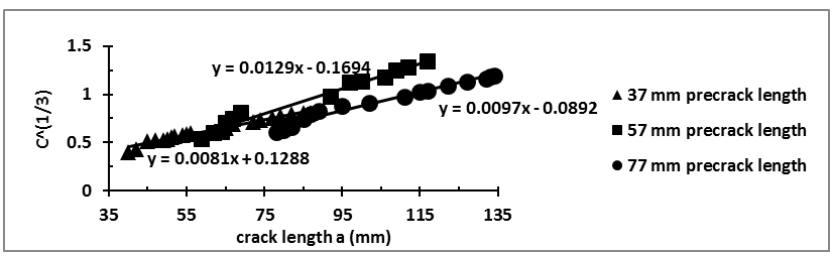

b

Fig. 4 Crack length versus $\mathrm{C}^{1 / 3}$ for specimens: a - room temperature; $\mathrm{b}-60^{\circ} \mathrm{C}$

\section{CC (Compliance Calibration) Method}

Generate a least squares plot of $\log \left(\delta_{i} / P_{i}\right)$ versus $\log \left(a_{i}\right)$ using the visually observed delamination onset values and all the propagation values. Draw a straight line through the data which results in the best least-squares fit (Fig. 5). Calculate the exponent $\mathrm{n}$ from the slope of this line according to $n=\Delta y / \Delta x$, where $\Delta y$ and $\Delta x$ are defined in Fig. 5. Mode I interlaminar fracture toughness is calculated as follow:

$$
G_{I C}=\frac{n \times P \times \delta}{b \times a} .
$$

MCC (Modified Compliance Calibration) Method

Generate a least squares plot of the delamination length normalized by specimen thickness, $a / h$, as a func- tion of the cube root of compliance, $C^{1 / 3}$, as shown in Fig. 6, using the visually observed delamination onset values and all the propagation values. The slope of this line is $A^{1}$ (Fig. 6). Mode I interlaminar fracture toughness is calculated as follows:

$$
G_{I C}=\frac{3 \times P^{2} \times C^{2 / 3}}{2 \times A^{1} \times b \times h}
$$
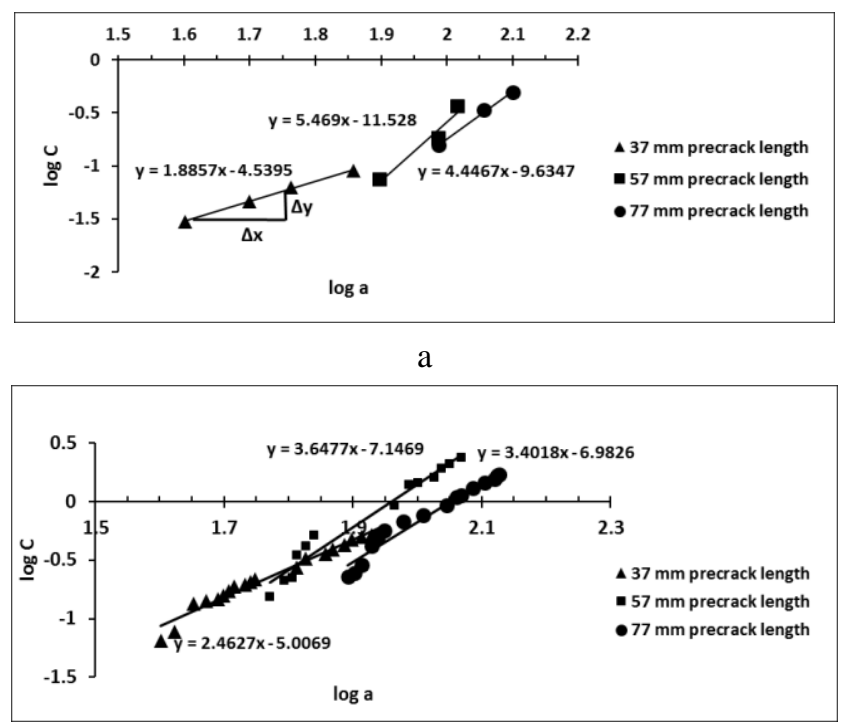

Fig. $5 \log \mathrm{C}-\log$ a for specimen: a - room temperature; $\mathrm{b}-60^{\circ} \mathrm{C}$

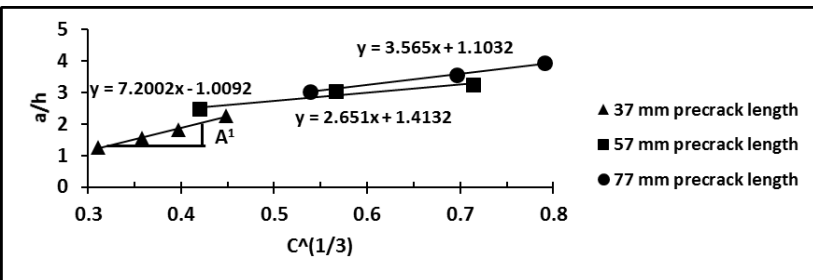

a

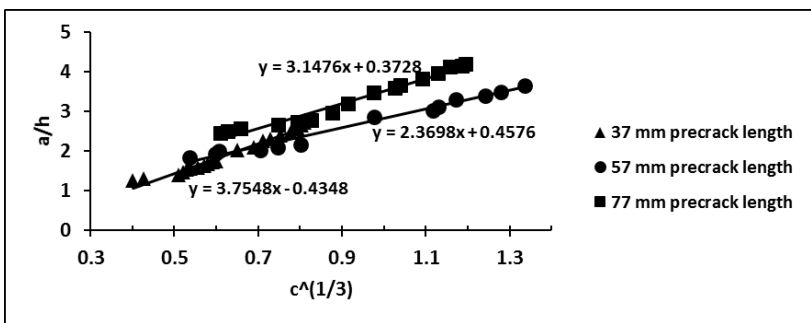

Fig. $6 a / h$ versus $C^{1 / 3}$ for specimen: a - room temperature; b $-60^{\circ} \mathrm{C}$

\section{Numerical analysis}

The virtual crack closure technique (VCCT) is widely used for computing energy release rates, based on results from continuum (2D) and solid (3D) finite element (FE) analyses. VCCT was first proposed by Rybicki and Kanninen [16] based on the principles of Linear elastic fracture mechanics (LEFM). It is an effective method in solving delamination problems and used in modelling delamination growth in composites [17]. Krueger [10] covers the technique and its applications extensively. 
VCCT is based on the assumption that the strain energy released in the crack propagation process is equal to the energy required to close the crack to its original state. The advantage of VCCT is its numerical simplicity and effectiveness. The calculation of Mode I strain energy release rate $G_{I}$ for each eight node element position along the delamination front can be summarized by the following equation:

$$
G_{I}=-\frac{1}{2 \Delta A} R_{Y} \Delta V,
$$

where $\Delta A$ is the crack extension area; $R_{Y}$ is the vertical force at the crack tip and $\Delta V$ is the vertical displacements between the top and bottom nodes of the crack face in $y$ direction. (Fig. 7).

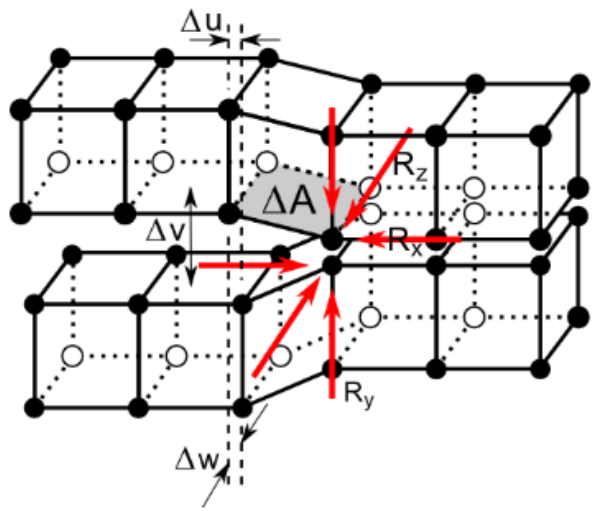

Fig. 7 VCCT for eight-node solid element [18]

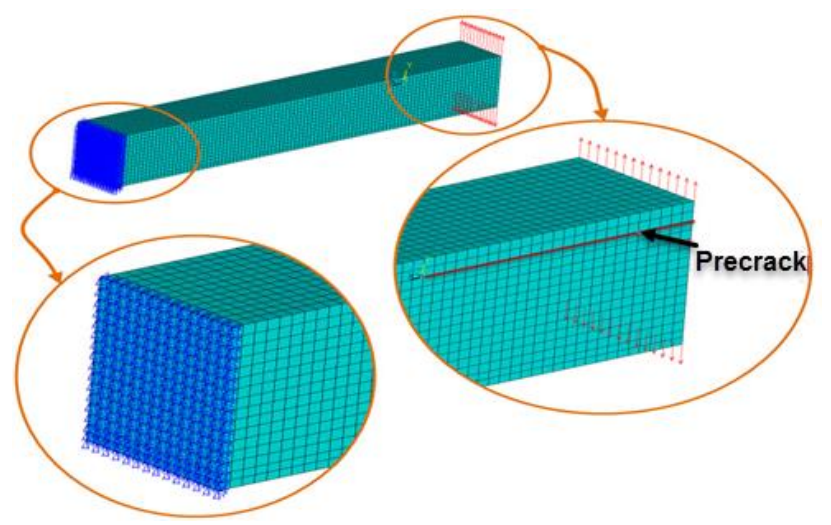

Fig. 8 3-D finite element model of DCB specimen

Mode I delamination was simulated using the Ansys 15 (Fig. 8). 3D finite element model (SOLID185, eight-node element) has been used for modelling of structure. Delamination is modelled as a discrete discontinuity in the plane between upper face sheet and foam of DCB specimen with separate unconnected nodes on the upper and lower surfaces of the delamination section. The upper face and lower face is divided into 1000 elements and core is divided into 2500 elements totally. The critical SERR has been calculated using the virtual crack closure technique (VCCT). Material properties used are shown in Tables 2 and 3. All dimensions and boundary conditions are similar to the real experimental set-up, in order to provide acceptable comparisons. In this section, the loads corresponding to the point of non-linearity of the loaddisplacement curve in the DCB specimen were used to calculate the critical strain energy release rates, using non- linear elastic finite element models and Ansys implementation of VCCT.

\section{Results and discussion}

In order to characterize the critical SERR, mean values were computed by using all the data over the entire range of effective crack length. The critical SERR was found by using all three methods; MBT, CC and MBC. Table 4 provides the computed values of strain energy release rate for three different methods and pre-crack values at room and high temperature and the characteristic SERR versus crack propagation for one of the specimen is given in Fig. 9. It is seen that after crack initiation, the SERR values were approximately constant for different three methods.

The effect of pre-crack length on the critical SERR (Glc) for DCB tests of sandwich composite specimens at room temperature is compared and the standard deviations from the mean value were shown in Fig. 10. The mean and standard deviation values are given in Table 4. DCB tests showed a negligible increase in critical SERR by increasing the pre-crack length. The specimens with $37 \mathrm{~mm}$ pre-crack length experienced a less SERR value (approximately $8 \%, 27 \%$ and $43 \%$ in MBT, CC and MCC methods, respectively) by comparing with $57 \mathrm{~mm}$ and $77 \mathrm{~mm}$ pre-crack length. Figure 10 also shows that the results of $\mathrm{CC}$ and $\mathrm{MBC}$ methods are close each other.

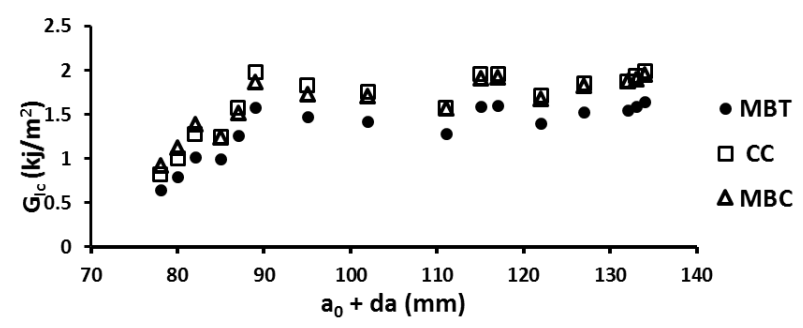

Fig. 9 Comparison of the critical SERR values $G_{I C}$ versus crack propagation for three methods for specimen with initial crack $a_{0}=77 \mathrm{~mm}$ at $60^{\circ} \mathrm{C}$ temperature

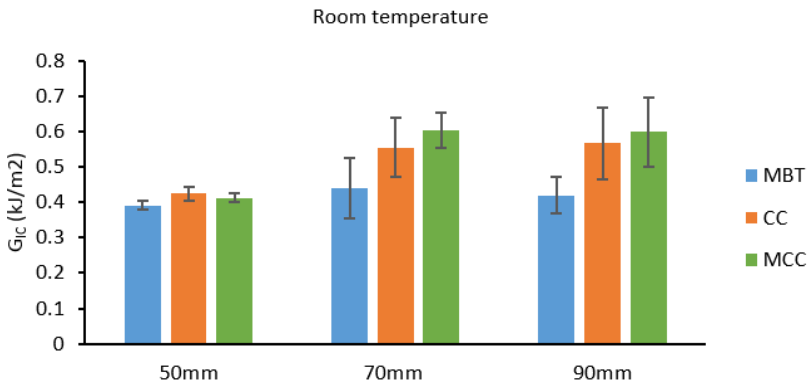

Fig. 10 Comparison of mean $G_{I C}$ calculated from the three methods at room temperature

The effect of pre-crack length on the critical SERR $(G l c)$ for DCB test specimens at $60^{\circ} \mathrm{C}$ is compared in Fig. 11 with the standard deviations from the mean value. The mean and standard deviation values are given in Table 4. DCB tests showed a negligible increase in critical SERR by increasing the pre-crack length as it is seen in high temperature $60^{\circ} \mathrm{C}$. The specimens with $37 \mathrm{~mm}$ precrack length experienced a less SERR value (approximately $11 \%, 13 \%$ and $14 \%$ in MBT, CC and MCC meth- 
ods, respectively) by comparing with $57 \mathrm{~mm}$ and $77 \mathrm{~mm}$ pre-crack length. Fig. 11 also shows that the results of $\mathrm{CC}$ and $\mathrm{MBC}$ are approximately close each other.

$$
60^{\circ} \mathrm{C}
$$

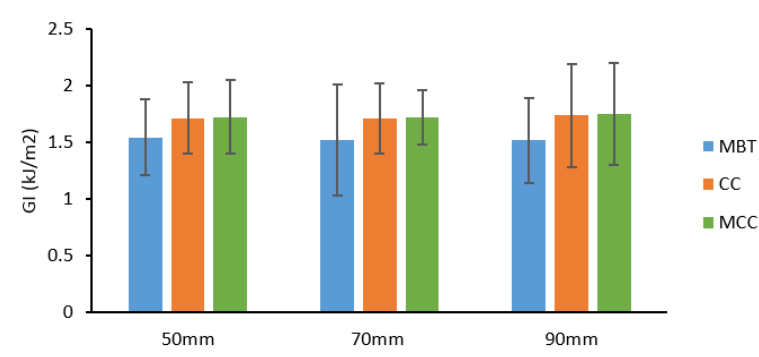

Fig. 11 Comparison of mean $G_{I C}$ calculated from the three methods at $60^{\circ} \mathrm{C}$
As seen in the Table 4, at room temperature, if we compare the MBT method with others, fair results were obtained with this method. The obtained results indicates that the pre-crack length has inconsiderable effect on the critical SERR value. The high temperature has considerable effect on the results of the SERR values. $37 \mathrm{~mm}$ precrack length of DCB tests at high temperature $\left(60^{\circ} \mathrm{C}\right)$ experienced approximately $75 \%, 71 \%$ and $72 \%$, reductions in MBT, CC and MCC methods, respectively by comparing results in room temperature. At high temperature we can see $57 \mathrm{~mm}$ and $77 \mathrm{~mm}$ as well as $37 \mathrm{~mm}$ pre-crack lengths showed $75 \%, 67 \%$ and $65 \% ; 76 \%, 65 \%$ and $66 \%$ reductions, respectively in $\mathrm{MBT}, \mathrm{CC}$ and $\mathrm{MCC}$ methods by comparing results in room.

Table 4

Critical SERR value of GFRP sandwich composites with different pre-crack length at different temperature

\begin{tabular}{|c|c|c|c|c|c|c|c|c|}
\hline \multirow{2}{*}{ Temperatures and pre-crack lengths } & \multicolumn{3}{|c|}{ Room temperature } & & \multicolumn{3}{c|}{$60^{\circ} \mathrm{C}$} \\
\cline { 2 - 8 } & & $37 \mathrm{~mm}$ & $57 \mathrm{~mm}$ & $77 \mathrm{~mm}$ & & $37 \mathrm{~mm}$ & $57 \mathrm{~mm}$ & $77 \mathrm{~mm}$ \\
\hline \multirow{3}{*}{$\begin{array}{c}\text { Mean } G_{I C}, \\
\mathrm{KJ} / \mathrm{m}^{2}\end{array}$} & MBT & 0.39 & 0.42 & 0.42 & & 1.54 & 1.71 & 1.72 \\
\cline { 2 - 9 } & CC & 0.44 & 0.56 & 0.59 & & 1.51 & 1.71 & 1.72 \\
\cline { 2 - 9 } & MCC & 0.42 & 0.60 & 0.60 & & 1.52 & 1.73 & 1.75 \\
\hline \multirow{2}{*}{$\begin{array}{c}\text { Std dev } G_{I C}, \\
\mathrm{KJ} / \mathrm{m}^{2}\end{array}$} & MBT & 0.44 & 0.58 & 0.58 & & 1.45 & 1.84 & 1.89 \\
\cline { 2 - 9 } & CC & 0.01 & 0.08 & 0.05 & & 0.05 & 0.12 & 0.25 \\
\cline { 2 - 9 } & MCC & 0.01 & 0.04 & 0.09 & & 0.26 & 0.23 & 0.17 \\
\hline
\end{tabular}

\section{Conclusions}

The objective of this work was to determine the mechanical properties and delamination resistance of the facesheets/core interface at room and high temperature of sandwich panels. The woven GFRP and PVC Airex ${ }^{\circledR}$ C70.55 were used as facesheets and core, respectively to produce the sandwich composite plate. The mechanical properties were obtained at room and high temperature. It is seen that the mechanical properties; Poisson's ratio, modulus of elasticity and shear modulus decrease with increasing temperature. Experiments were performed to determine the effect of temperature and pre-crack length on the interfacial toughness of sandwich composites. MBT, $\mathrm{CC}$ and MCC methods were used to investigate the critical SERR, GIC, from experimental results of DCB tests. The virtual crack closure technique (VCCT) was used and 3D finite element analysis has been performed to obtain the SERR value of specimens for various pre-crack lengths. It is seen that there is a good agreement between CC, MCC and VCCT. Therefore, VCCT analysis is to be an appropriate method for analyzing a SERR value of sandwich composites. Examining the SERR results from all methods of sandwich materials, it is determined that $\mathrm{G}_{\mathrm{IC}}$ depends on test temperature. If the SERR values at high temperature $\left(60^{\circ} \mathrm{C}\right)$ are compared with the SERR values at room temperature $\left(23^{\circ} \mathrm{C}\right)$, it is seen that the results obtained at high temperature are fairly large with respect to room temperature. It is significant that SERR value increases with an increase in temperature. Fracture toughness parameter depends on temperature effect [19]. Therefore, DCB test results provided that high temperature has significant effect on the Mode I interlaminar fracture toughness of sandwich composites.
It is also concluded that long pre-crack length has negligible effect on the SERR value in DCB tests. In other words, the Mode I interlaminar fracture toughness of sandwich composites was unaffected by pre-crack length. Good agreement has been found between fracture toughness values determined using finite element method VCCT and experimental DCB tests.

\section{References}

1. Bakis, C.E.; Bank, L.C.; Brown, V.L.; Cosenza, E.; Davalos, J.F.; Lesko, J.J. 2002. Fiber-reinforced polymer composites for construction - State-of-the-art review, J. Compos. Constr. 6: 73-87. http://dx.doi.org/10.1061/(ASCE)10900268(2002)6:2(73).

2. Laksimi, A.; Benzeggagh, M.L.; Jing, G.; Hecini, M.; Roelandt, J.M. 1991. Mode I interlaminar fracture of symmetrical cross-ply composites, Compos. Sci. Technol. 41: 147-164. http://dx.doi.org/10.1016/0266-3538(91)90025-K.

3. Pradeep, K.R.; Nageswara, B.; Rao, S.M.; Srinivasan, K. 2012. Interface fracture assessment on honeycomb sandwich composite DCB specimens, Eng. Fract. Mech. 93: 108-118.

http://dx.doi.org/10.1016/j.engfracmech.2012.06.011.

4. Pan, S.D.; Wu, L.Z.; Sun, Y.G.; Zhou, Z.G. 2008. Fracture test for double cantilever beam of honeycomb sandwich panels, Mater. Lett. 62: 523-526. http://dx.doi.org/10.1016/j.matlet.2007.05.084.

5. Adams, D.O.; Kessler, J.; Nelson, J.; Bluth, J.; Kuramoto, B. 2010. Development and Evaluation of Fracture Mechanics Test Methods for Sandwich Composites, in: Proc. FAA JAMS Tech. Rev. Meet. Wichita, 
$\mathrm{KS}$

6. Veazie, D.R.; Robinson, K.R.; Shivakumar, K. 2004. Effects of the marine environment on the interfacial fracture toughness of PVC core sandwich composites, Compos. Part B Eng. 35: 461-466. http://dx.doi.org/10.1016/j.compositesb.2003.09.004.

7. Soni, S.M.; Gibson, R.F.; Ayorinde, E.O. 2009. The influence of subzero temperatures on fatigue behavior of composite sandwich structures, Compos. Sci. Technol. 69: 829-838. http://dx.doi.org/10.1016/j.compscitech.2008.02.007.

8. Gates, T.S.; Su, X.; Abdi, F.; Odegard, G.M.; Herring, H.M. 2006. Facesheet delamination of composite sandwich materials at cryogenic temperatures, Compos. Sci. Technol. 66: 2423-2435. http://dx.doi.org/10.1016/j.compscitech.2006.01.028.

9. Liechti, K.M.; Marton, B. 2002. Delamination of a high-temperature sandwich plate, Exp. Mech. 42: 206213. http://link.springer.com/article/10.1007/BF02410885. http://dx.doi.org/10.1007/BF02410885.

10. Krueger, R. 2004. Virtual crack closure technique: History, approach, and applications, Appl. Mech. Rev. 57: 109-119. http://dx.doi.org/10.1115/1.1595677.

11. Krueger, R. 2006. Computational fracture mechanics for composites-State of the art and challenges, NAFEMS Nord. Semin. Predict. Model. Fail. Using FEA.

12. D3039M/D3039M-14, Standard test method for tensile properties of polymer matrix composite materials, Annu. B. ASTM Stand. (2013) 1-13.

13. Standard Test Method for In-Plane Shear Response of Polymer Matrix Composite Materials by Tensile Test of a $645^{\circ}$ Laminate 1. 2007. Society. 94: 1-7.

14. Durakbasa, M.N.; Osanna, P.H.; Demircioglu, P. 2011. The factors affecting surface roughness measurements of the machined flat and spherical surface structures - The geometry and the precision of the surface, Meas. J. Int. Meas. Confed. 44: 1986-1999. http://dx.doi.org/10.1016/j.measurement.2011.08.020.

15. ASTM Standard, D5528-01 2001. 2014. Standard Test Method for Mode I Interlaminar Fracture Toughness of Unidirectional Fiber-Reinforced Polymer Matrix Composites, Am. Soc. Test. Mater. 1-13.

16. Rybicki, E.F.; Kanninen, M.F. 1977. A finite element calculation of stress intensity factors by a modified crack closure integral, Eng. Fract. Mech. 9: 931-938. http://dx.doi.org/10.1016/0013-7944(77)90013-3.
17. Shen, F.; Lee, K.H.; Tay, T.E. 2001. Modeling delamination growth in laminated composites, Compos. Sci. Technol. 61: 1239-1251. http://dx.doi.org/10.1016/S0266-3538(01)00023-9.

18. I. ANSYS ${ }^{\circledR}$ Academic Research, Release 15, Help System, Structural Analysis Guide, ANSYS, ANSYS, (n.d.) http://www.ansys.com.

19. Anderson, T.L. 2005. Fracture Mechanics: Fundamentals and Applications, Third Edition, 640 p.

Meltem Evren Toygar, Farshid Khosravi Maleki

\section{THE TEMPERATURE AND PRE-CRACK LENGTH EFFECTS ON DELAMINATION RESISTANCE OF WOVEN GFRP SANDWICH COMPOSITES}

S u m m a r y

In this paper, the temperature and pre-crack effects on the delamination resistance of woven glass fibre reinforced polymer (GFRP) sandwich composites under Mode I loading was experimentally investigated and numerically modelled. For this purpose, the sandwich composite panel was fabricated with vacuum assisted resin infusion molding (VARIM). The mechanical properties were obtained at room and high temperature. Double cantilever beam (DCB) test was adopted for the measurement of delamination resistance by evaluating the strain energy release rate (SERR) value to obtain the fracture properties of woven GFRP sandwich composites. The three analytical methods, the experimental compliance calibration method (CCM), Modified Compliance Calibration Method (MCC) and Modified Beam Theory (MBT) have been used. In the finite element analysis virtual crack closure technique (VCCT) was used. The results obtained from 3D finite element analysis for various delamination lengths compare well with the experimental results. It is seen that there is an agreement between experimental and numerical results so that VCCT analysis is to be an appropriate method for analysing a SERR value of sandwich composites.

Keywords: Interlaminar fracture toughness, woven GFRP sandwich composites, DCB test method, virtual crack closure technique (VCCT).

Received April 07, 2016

Accepted September 07, 2016 